\title{
EXECUTARÉ PRECISO, PLANEJAR NÃO É PRECISO: PROPOSTA DE FRAMEWORK PARA PROJETOS DE PESQUISA
}

\author{
EXECUTING IS NEEDED, PLANNING IS NOT NEDDED: PROPOSAL OF
}

FRAMEWORK FOR RESEARCH PROJECTS

Recebido em: 08/09/2017 - Aprovado em: 27/11/2017

Avaliado pelo sistema double blind review

Editor Científico: Edson Sadao Iizuka

DOI 10.13058/raep.2018.v19n1.765

\section{ALESSANDRO PRUDÊNCIO LUKOSEVICIUS alessanpl@gmail.com}

\author{
UNIVERSIDADE FEDERAL FLUMINENSE
}

\section{RESUMO}

A qualidade do projeto de pesquisa influencia o rigor teórico-metodológico e a contribuição de valor do trabalho científico produzido. O design inadequado e a falta de maturação dos projetos de pesquisa são alguns dos problemas que mais levam à rejeição direta de artigos, mormente, nas áreas de administração, contabilidade e turismo. Mas, apesar da importância, muitas vezes, essa etapa é negligenciada e tratada de forma descuidada. Por isso, este artigo propõe a uma abordagem gráfica para projetos de pesquisa que pode auxiliar pesquisadores, sobretudo, iniciantes, a planejarem suas pesquisas. Para cumprir tal objetivo, conjugou-se revisão da literatura com análise de conteúdo, tendo por referência artigos e livros da área metodológica. Como resultado, desenvolveu-se o Research Project Model Canvas (RPMC), um framework que provê direcionamento ao pesquisador, auxiliando-o a evitar erros, mas sem lhe suprimir a criatividade e o espaço da tomada de decisão.

Palavras-Chave: Método científico. Projeto de pesquisa. Metodologia de pesquisa. Método de pesquisa. Modelo canvas.

\begin{abstract}
The quality of the research project influences the theoretical-methodological rigor and the value contribution of the scientific work produced. The inadequate design and the lack of maturation of research projects are some of the main problems leading to the direct rejection of articles, mainly in the area of administration, accounting, and tourism. However, despite the importance, these steps are often neglected and carelessly handled. Thus, this article proposes a graphical approach to research projects that may help researchers, especially the beginners, to plan their research. To fulfill this objective, a literature review was combined with content analysis, with reference to articles and books of the methodological area. As a result, the Research Project Model Canvas $(R P M C)$ was developed, a framework that provides guidance to the researcher, helping to avoid errors, without suppressing the creativity and space of decision making.

Keyword: Scientific method. Research project. Research methodology. Research method. Canvas model.
\end{abstract}




\section{INTRODUÇÃO}

A atividade de pesquisa é empreendida com o intuito de construir novos conhecimentos e, para tal, é necessário projetar o caminho a ser seguido (FIGUEIREDO, 2008). Este projeto de pesquisa pode ser entendido como um empreendimento temporário para alcançar o conjunto das metas estabelecidas na pesquisa em respeito a uma justificativa científica (GIL, 2010; AXELOS, 2017). Por conseguinte, o projeto de pesquisa norteia a investigação no alcance dos objetivos traçados tendo como referência uma questão de pesquisa (GODOY, 1995; MERRIAM, 1998; WALDEMAR et al., 2007).

Assim, o projeto de pesquisa tem um grande impacto na qualidade do trabalho final (FERREIRA, 2015). Por exemplo, nas áreas de administração, contabilidade e turismo, a insuficiente maturação dos projetos de pesquisa explica boa parte das deficiências apontadas nos trabalhos por editores de periódicos (FALASTER; FERREIRA; CANELA, 2016). Para Ferreira (2015), a relação entre um projeto de pesquisa mal planejado e os resultados insatisfatórios das pesquisas derivadas, ocorre também em outras áreas de conhecimento.

Nessa direção, os rigores teórico e metodológico e a contribuição de valor são apontados como fundamentais para se produzir um trabalho com qualidade científica (BACHARACH, 1989; WHETTEN, 1989; PENDERGAST, 2007). Não obstante, harmonizar os três aspectos é um desafio, pois às vezes os pesquisadores tratam a elaboração do projeto de pesquisa de forma descuidada (FERREIRA, 2015).

Portanto, justificar a elaboração de um projeto de pesquisa confunde-se com a justificativa do próprio ato de planejar (FIGUEIREDO, 2008), afinal, assim como não se deveria construir um prédio sem uma planta, não se deveria pesquisar sem projeto (FIGUEIREDO, 2008). Além disso, empregar técnicas visuais (por exemplo, gráficos) permite construir e discutir significados, facilitando a estruturação mental e a comunicação (OSTERWALDER; PIGNEUR, 2011) dos elementos da pesquisa.

Dessa maneira, dada a necessidade de elaborar um projeto de pesquisa, destaca-se a preocupação de encontrar novas formas para melhor estru- 
turá-lo. Logo, este artigo propõe uma abordagem gráfica para projetos de pesquisa que pode auxiliar pesquisadores, a planejarem suas pesquisas. Para cumprir tal objetivo, executou-se a coleta de dados por meio de revisão da literatura e a análise dos resultados deu-se por análise de conteúdo, tendo por referência artigos e livros da área metodológica. Como resultado, desenvolveu-se o Research Project Model Canvas (RPMC), um framework para projetos de pesquisa que pode auxiliar pesquisadores, mormente, iniciantes a planejarem suas pesquisas.

Além desta introdução, este artigo apresenta a revisão da literatura sobre projetos de pesquisa. Feito isso, os procedimentos metodológicos são elucidados e os resultados são apresentados e analisados, culminando com a concepção e exemplificação do framework. Como fechamento, apresentam-se as considerações finais, limitações do trabalho e sugestões de estudos futuros. 


\section{REVISÃO DA LITERATURA}

Inicialmente, vale destacar que o paradigma adotado pelo pesquisador influencia o conteúdo do projeto de pesquisa. Entende-se por paradigma as crenças compartilhadas pelos membros de uma comunidade científica (GIL, 2009) que circunscrevem a visão filosófico-científica (epistemologia) que será adotada por um pesquisador (MARSCH; FURLONG, 2002). Assim, Orlikowski e Baroudi (1991) classificam os estudos nos paradigmas: (1) positivista, sendo que a realidade é fixa e pode ser medida pelo pesquisador por meio de instrumentos; (2) interpretativista, sendo que as pessoas são construtoras da realidade e que cabe ao pesquisador interpretar essa realidade; e (3) crítico, sendo que o pesquisador é um agente que deve interferir na realidade estudada para dar visibilidade ao coletivo da sociedade sobre os mecanismos de manipulação encapsulados no status quo.

Em termos de estrutura, os elementos, normalmente, solicitados em projetos de pesquisa são (FIGUEIREDO, 2008; GIL, 2010; RICHARDSON et al., 2010): (a) formulação do problema; (b) explicitação do quadro teórico; (c) construção de hipóteses ou especificação dos objetivos; (d) identificação do tipo de pesquisa; (e) operacionalização das variáveis; (f) seleção da amostra; (g) determinação da estratégia de coleta de dados; (h) planejamento da análise dos resultados; (i) previsão da forma de apresentação dos resultados; (j) cronograma da execução da pesquisa e (l) definição dos recursos humanos, materiais e financeiros a serem alocados. Esses elementos são contemplados na revisão da literatura a seguir.

\section{TÍTULO DA PESQUISA}

É recomendável a definição de um título quando o projeto de pesquisa se inicia, pois mantém o pesquisador focalizado no estudo (CRESWELL, 2010). Além disso, é comum o título sofrer refinamentos ao longo da escrita do projeto para se alinhar com a lógica da pesquisa.

Naturalmente, o título tende a ser o primeiro item do trabalho a ser lido e, por isso, concorre para o sucesso na publicação (FERREIRA, 2015), além de influenciar o desejo do leitor em continuar lendo o trabalho. Por 
isso, o título deveria gerar impacto (CRESWELL, 2010), mas sem ser enganoso (VOLPATO, 2011).

O título deveria ser uma frase curta, com elevado poder descritivo e compreensível para leitores de áreas correlatas a estudada (VOLPATO, 2011) e para o público em geral. Além disso, para o autor, é recomendado que o título expresse o que o trabalho tem de mais relevante (a descoberta, a novidade ou a contribuição). Portanto, a redação do título pode guiar-se pela conclusão, pelo objetivo, pelo problema ou pelas variáveis conceituais, dependendo daquilo que tiver potencial de atrair mais a atenção dos leitores. Exemplos de títulos com base em: (1) conclusão: estresse prejudica memorização em adolescentes; (2) objetivo: efeitos do fumo e da poluição por aerossol na cobertura das nuvens; (3) problema: por que existem tantas espécies de insetos herbívoros nas florestas tropicais?; (4) variáveis conceituais: escovação dos dentes, inflamações e os riscos de doenças cardiovasculares.

Volpato (2011), quando comenta alguns mitos sobre o título, atesta que ele pode ser uma pergunta, pode conter a palavra "efeito" e pode conter verbo. Vale, também, apontar algumas práticas não recomendadas ao escrever um título: (1) usar palavras que não remetam à essência da contribuição ou novidade (FIGUEIREDO, 2008). Por exemplo, "Um estudo sobre...", "Compreendendo a...", "Algumas observações sobre..."; (2) incluir a região onde a pesquisa foi feita, a menos que o local seja a novidade (VOLPATO, 2011); (3) terminar com ponto final ou usar referências (VOLPATO, 2011) e (4) utilizar artigos (“O”, "A", "Um”, “Uma”), abreviações, fórmulas, nomes próprios ou jargões (BURSZTYN; DRUMMOND; NASCIMENTO, 2010). Dessa forma, o título sintetiza o valor do trabalho, além de servir como referência conceitual para os demais elementos do projeto de pesquisa.

\section{TEMA DE PESQUISA}

O tema é o assunto que se deseja estudar, portanto, circunscreve o contexto da grande área de pesquisa (FIGUEIREDO, 2008) e delimita o foco do estudo (RICHARDSON et al., 2010). Por exemplo, (1) novas tecnologias e 
capacitação docente e (2) avaliação de livros didáticos de ciências (COSTA; COSTA, 2011).

Para Cajueiro (2015), a delimitação do tema é fundamental, pois se trata de um recorte na imensa quantidade de conteúdos relacionados a um assunto. Afinal, é preferível realizar um recorte da realidade do que se perder em um mundo de informações impossíveis de serem tratadas (MINAYO, 1994; BARRETO; HONORATO, 1998).

A escolha do tema pode emergir de diversas fontes, por exemplo, a observação do cotidiano, a prática profissional, os programas de pesquisa, o contato e relacionamento com especialistas e a revisão da literatura (BARROS; LEHFELD, 2007).

Lakatos e Marconi (2010) propõem que fatores internos e externos podem interferir na escolha do tema. Pode-se citar como fatores internos: preferências pessoais do pesquisador (afetividade em relação ao tema) (WALDEMAR et al., 2007), tempo disponível para a realização do trabalho (MASCARENHAS, 2012) e capacidade do pesquisador em realizar o trabalho (WALDEMAR et al., 2007). Já para os fatores externos, pode-se citar: valor acadêmico e social (deve interessar a outros) (FIGUEIREDO, 2008), grau de novidade (FIGUEIREDO, 2008) e recursos financeiros disponíveis (MASCARENHAS, 2012). Portanto, sugere-se que o tema seja original, importante e viável (VIEIRA, 2008; VOLPATO, 2011).

\section{JUSTIFICATIVA DA PESQUISA}

A justificativa é dada pela fundamentação do porquê realizar a pesquisa, isto é, as contribuições (acréscimos), a importância, os benefícios e as vantagens da pesquisa (FIGUEIREDO, 2008). A justificativa deverá convencer o leitor acerca da necessidade da pesquisa proposta (HADDAD, 2004; CAJUEIRO, 2015), portanto, deve ser um texto formulado com elementos racionais e persuasivos.

O ponto central da justificativa é ressaltar a novidade do estudo (BARRAL, 2003; VOLPATO, 2011), por exemplo, quando o estudo é contraintuitivo (desafia a sabedoria popular) (PENDERGAST, 2007) ou paradoxal (em face da teoria devia ser $\mathrm{X}$, no entanto os resultados levam a 
Y) (FERREIRA, 2015); ou quando identifica uma lacuna de conhecimento (isto é, aquilo que não está bem-esclarecido, bem-entendido e necessita de mais pesquisas).

Em termos estruturais, para Pendergast (2007) e Figueiredo (2008), a relevância do estudo deve ser mostrada nos aspectos técnico, científico e social, abrangendo as perspectivas teórica e prática.

\section{PROBLEMA DE PESQUISA}

Como visto, um tema não constitui um problema de pesquisa, então, a problematização ocorre quando se formula perguntas sobre o tema (COSTA; COSTA, 2011). A tentativa de respondê-las é que leva à realização da pesquisa. Assim, o problema de pesquisa pode ser entendido como uma dificuldade teórica ou prática para a qual se busca solução (MASCARENHAS, 2012).

Pelo posto, o problema deveria ser escrito na forma de pergunta e o planejamento deveria ser realizado de maneira a resolvê-lo. Assim, o problema norteia a pesquisa e assume a função de: (1) levar o pesquisador à reflexão sobre o tipo de estudo a desenvolver; (2) orientar o levantamento bibliográfico e (3) orientar a coleta de dados (MASCARENHAS, 2012).

A escolha do problema, assim como do tema, decorre de certas características do pesquisador, tais como: conhecimento e experiência no assunto, criatividade, curiosidade, sensibilidade, perseverança e determinação (MARTINS, 2010; COSTA; COSTA, 2011). Logo, para formular o problema, dever-se-ia: (1) aprofundar sistematicamente no objeto de estudo; (2) realizar um estudo da literatura existente sobre o tema e (3) discutir com pessoas que acumularam experiência prática no campo de estudo (SELLTIZ, 2010 apud GIL). Ademais, recomenda-se que o estudo tenha uma única pergunta principal, apesar de perguntas secundárias serem permitidas (PERNEGER; HUDELSON, 2004).

Segundo Vergara (2004), Perneger e Hudelson (2004), Lakatos e Marconi (2010) e Gil (2010), o problema (pergunta) de pesquisa deveria ser: (a) formulado como pergunta aberta: não deve permitir respostas do tipo "sim" ou "não", pois elas não instigam a realizar testes; (b) claro, ob- 
jetivo e preciso: os conceitos e termos usados em sua enunciação não devem ser ambíguos nem gerar dúvidas; (c) empírico (científico): pode ser eficazmente resolvido por meio de pesquisa, ou seja, é observável e testável na realidade por meio de técnicas e métodos apropriados. Vale ressaltar que, para ser científico, o problema não deve envolver juízo de valor (fruto de opinião) nem focalizar em como fazer algo de forma eficiente; (d) suscetível de solução: isto é, as variáveis do problema devem permitir observação ou manipulação, assim como levar a uma conclusão válida; (e) viável para pesquisa: isto é, existem recursos para pesquisar, principalmente, em termos de tempo e custo; (f) capaz de trazer conhecimentos novos; e (g) relevante para uma ampla parcela da comunidade científica. O Quadro 1 apresenta exemplos de problemas inadequados para pesquisa com os respectivos defeitos.

Quadro 1 Exemplos de problemas inadequados para pesquisa

\begin{tabular}{|c|c|}
\hline Problema & DeFEITOS \\
\hline $\begin{array}{l}\text { 1. O aumento de salário do pro- } \\
\text { fessor é capaz de melhorar os } \\
\text { resultados dos alunos? } \\
\text { 2. Qual é a melhor técnica de en- } \\
\text { sino? } \\
\text { 3. O que pensam os idosos? } \\
\text { 4. Há vida em Marte? } \\
\text { 5. Como resolver os problemas } \\
\text { das enchentes em São Paulo? } \\
\text { 6. Qual o procedimento mais prá- } \\
\text { tico para se armazenar dados } \\
\text { num microcomputador? } \\
\text { 7. Quais as causas da delinquência } \\
\text { infantil? } \\
\text { 8. Qual o vestuário dos universitá- } \\
\text { rios? }\end{array}$ & $\begin{array}{l}\text { 9. Pergunta do tipo "sim" ou } \\
\text { "não" } \\
\text { 10. Contém juízo de valor. Falta } \\
\text { precisão. } \\
\text { 11. Falta delimitação (muito gené- } \\
\text { rico). } \\
\text { 12. Ausência de elementos empíri- } \\
\text { cos. } \\
\text { 13. Trata-se de problema do tipo } \\
\text { "como fazer" } \\
\text { 14. Trata-se de problema do tipo } \\
\text { "como fazer" } \\
\text { 15. Falta delimitação (muito gené- } \\
\text { rico) e uma dimensão viável. } \\
\text { 16. Sem importância científica. }\end{array}$ \\
\hline
\end{tabular}

Fonte: Adaptado de Martins (2010, p. 24) 
Para Volpato (2011), de maneira geral, as perguntas de pesquisa podem ser divididas em três grupos: (1) como o fenômeno é: por exemplo, quais as características das pessoas que se divorciam?; (2) com o que o fenômeno está associado: por exemplo, a modalidade predominante de liderança tem que ver com a cultura organizacional? e (3) no que esse fenômeno interfere ou o que interfere nesse fenômeno: por exemplo, em que medida a escolaridade influencia na preferência político-partidária?.

\section{OBJETIVOS DA PESQUISA}

Se o problema de pesquisa é a questão a ser investigada, o objetivo é o resultado a ser alcançado (VERGARA, 2004). Disso decorre que, alcançado o objetivo, responde-se ao problema. Em adição, os objetivos, quando quantificados, recebem o nome de metas (COSTA; COSTA, 2011).

No entendimento de Waldemar et al. (2007), os objetivos dividem-se em dois tipos:

- Objetivo geral: também denominado objetivo final, refere-se ao que se quer alcançar no final da pesquisa, ou seja, trata do "para que” fazer a pesquisa. É definido a partir do problema de pesquisa e deve ter uma amplitude que possibilite responde-lo e verificar a hipótese/pressuposto (se houver).

- Objetivos específicos: também denominados objetivos intermediários, representam as etapas da pesquisa que levarão à realização do objetivo geral. Assim, esses objetivos descrevem o caminho lógico (ciclo de vida da pesquisa) a ser percorrido para solucionar o problema. Eles podem: (1) ser definidos com base nos termos-chaves do objetivo geral e (2) ser declarados como pergunta.

Vale ressaltar que uma pesquisa, normalmente, possui apenas um objetivo geral e tantos objetivos específicos quantos necessários (COSTA; COSTA, 2011). A declaração dos objetivos específicos é comum no caso de monografias (por exemplo, dissertações e teses), mas não costumam aparecer explicitamente em artigos. 
Recomenda-se que os objetivos sejam escritos com verbo no infinitivo e de forma direta (MARTINS, 2010; COSTA; COSTA, 2011). No entanto, alerta Martins (2010), os verbos devem transmitir a ação de investigação (por exemplo, identificar, verificar, descrever e avaliar) e não de execução (por exemplo, construir, resolver e facilitar). Nessa direção, Gil (2010) sugere utilizar verbos mais claros e específicos, evitando verbos "genéricos”, tais como: pesquisar, entender e conhecer.

Para a definição do problema de pesquisa e consequentes objetivos geral e específicos, Vergara (2004) oferece o exemplo:

- Problema: quais são os fatores que contribuem para a migração rural-urbana no estado da Paraíba?

- Objetivo geral: verificar os fatores que contribuem para a migração rural-urbana no estado da Paraíba

- Objetivos específicos:

- (a) Levantar informações sobre a migração rural-urbana no estado da Paraíba.

- (b) Identificar fatores que contribuem para essa migração.

- (c) Comparar a importância dos fatores que contribuem para a migração rural-urbana no estado da Paraíba.

\section{REFERENCIAL TEÓRICO}

Existem muitas expressões para representar essa seção do projeto de pesquisa, por exemplo, marco teórico, quadro teórico, fundamentação teórica, quadro conceitual, revisão da literatura ou revisão bibliográfica. Entretanto, para fins deste trabalho, essas expressões são consideradas conceitualmente semelhantes e, por essa razão, adotou-se o termo referencial teórico.

No referencial teórico, apresentam-se os estudos realizados por outros autores sobre o tema ou o problema (VERGARA, 2004) em um nível de detalhe em que o leitor tenha condições de obter conhecimento suficiente para entender a pesquisa. Deve-se buscar as fronteiras do conhecimento (estado da arte), pois tal medida visa evitar a duplicação de pesquisas sobre o mesmo enfoque. Nesse percurso, passa-se pelas referências clássicas, por exemplo, os primeiros artigos e livros sobre o assunto, seguindo em dire- 
ção aos estudos mais recentes sobre o tema/problema. Para Richardson et al. (2010), as referências devem estar adequadas e atualizadas, sendo, de preferência, $50 \%$ delas dos últimos cinco anos.

O referencial teórico é marcado pela discussão crítica das obras citadas. Assim, sugere-se: (a) reunir ideias comuns, (b) conectar ideias complementares entre si, (c) comparar ideias divergentes ou opostas e (d) identificar lacunas ou pontos frágeis (VERGARA, 2004). Portanto, sugere-se que essa seção seja escrita de tal maneira que os autores dialoguem entre si, tendo o pesquisador como mediador, isto é, o pesquisador deve apresentar sua voz no trabalho (MASCARENHAS, 2012).

Ademais, o pesquisador emoldura conceitualmente o tema, conectando a bibliografia pesquisada com o problema que está sendo estudado e facilitando a redação do trabalho. Nesse sentido, recomenda-se que o referencial teórico siga uma estrutura hierárquica, indo do assunto mais geral para o mais específico, assim como se utilize de tabelas e figuras para representar os conceitos advindos da literatura.

Outras funções do referencial teórico (VERGARA, 2004): (a) prover maior clareza na formulação do problema; (b) facilitar a formulação de hipóteses e suposições; (c) indicar o melhor método para a solução do problema; (d) indicar o melhor procedimento para coleta e tratamento dos dados e (e) apoiar a interpretação dos dados coletados.

Ferreira (2015) alerta para três dificuldades ao escrever a revisão da literatura: (1) realizar uma revisão muito abrangente e pouco contributiva para o problema de pesquisa; (2) não realizar uma revisão teórica, mas uma análise dos resultados empíricos de trabalhos existentes e (3) organizar o texto por autor e não por tópico.

Vale dizer que é do referencial teórico que, geralmente, derivam-se as palavras-chave do trabalho, aumentando a visibilidade dele, pois são utilizadas como indexadores em bases de dados.

\section{HIPÓTESES OU PRESSUPOSTOS DA PESQUISA}

Depois de definido o problema de pesquisa, este pode ser desmembrado em uma ou mais hipóteses (FIGUEIREDO, 2008). A hipótese é uma respos- 
ta - temporária e não testada empiricamente - para a pergunta de pesquisa (LAKATOS; MARCONI, 2010). Assim, a função da hipótese na pesquisa científica é servir de guia para a investigação, propondo explicações para certos fatos e, ao mesmo tempo, orientando a busca de outras informações (LAKATOS; MARCONI, 2010). Em pesquisas com abordagem qualitativa, a hipótese também é conhecida como pressuposto ou suposição, pois o termo hipótese tem uma conotação enraizada na abordagem quantitativa (MINAYO, 1994; VERGARA, 2004).

As hipóteses podem surgir de fontes como (GIL, 2010; COSTA; COSTA, 2011): resultados de outras pesquisas, senso comum, teorias, observações, intuição ou experiência do pesquisador. Assim, a hipótese é uma afirmação categórica verossímil que, uma vez confirmada, passa a ser a resposta do problema. Por consequência, como a hipótese é uma tentativa de explicar um fenômeno, a aceitação da hipótese poderá ser entendida como o embrião de uma nova teoria (MASCARENHAS, 2012).

Quando colocadas à prova, as hipóteses podem se configurar verdadeiras ou falsas. No entanto Volpato (2011) alerta para a possível existência de preconceito científico no caso de trabalhos em que a hipótese seja falsa. Dessa maneira, orienta o autor, deve-se mostrar, na introdução, as razões que tornaram a hipótese extremamente provável; nos resultados, deve-se provar que ela não se sustentava; e, na discussão, deve-se indicar que o contexto teórico era favorável à hipótese (ou seja, algo do contexto deve estar errado e esse é o avanço científico). Quando uma hipótese for parcialmente verdadeira, deve-se entender porque não foi verdadeira por completo, assim, buscando uma explicação geral (VOLPATO, 2011). No caso de haver diversas hipóteses, Volpato (2011) recomenda testar primeiro as hipóteses mais simples e, em seguida, as mais complexas.

Para uma hipótese ser considerada aplicável, deve apresentar determinadas características (MINAYO, 1994; LAKATOS; GIL, 2010; MARCONI, 2010): (1) conter variáveis definidas operacionalmente, isto é, conter variáveis que possam ser medidas e haja técnicas adequadas de coleta de dados que permitam o teste e eventual negação da hipótese; (2) não permitir julgamento de valor, por exemplo, quando se emprega termos como: mau, 
bom, deve, deveria e outros; (3) ser simples, isto é, escrita em linguagem que expresse exatamente a teoria que será testada por meio da pesquisa científica. Aliás, a clareza da definição dos termos da hipótese é fundamental para o desenvolvimento da pesquisa; e (4) se possível, estar relacionada a uma teoria, pois possuiria maior poder de explicação, além de facilitar a generalização.

As pesquisas exploratórias e descritivas (quando descrevem fenômenos) não exigem hipóteses. No caso, as pesquisas exploratórias visam obter informações sobre um assunto ainda pouco conhecido para apresentar novas ideias e, assim, propor hipóteses. Já as pesquisas descritivas descrevem fenômenos, portanto, as hipóteses ficam subentendidas e normalmente indicadas nos objetivos da pesquisa (GIL, 2010). No entanto, na pesquisa descritiva, a ausência de hipótese ocorre apenas quando o objetivo é descrever um fenômeno ou variável, pois, no caso de estudar associações entre variáveis, a hipótese é exigida.

As hipóteses são constituídas por associações entre variáveis (MASCARENHAS, 2012) que podem ser com ou sem interferência. Por exemplo, são hipóteses de (VOLPATO, 2011): (1) associação entre variáveis sem interferência: países economicamente desenvolvidos apresentam baixos níveis de analfabetismo e (2) associação de variáveis com interferência: a classe social da mãe influencia no tempo de amamentação dos filhos.

\section{VARIÁVEIS DE PESQUISA}

As hipóteses são compostas pelo relacionamento entre variáveis (GIL, 2010). Assim, a variável refere-se a fatores ou características que se pode medir por meio de valores objetivos (MASCARENHAS, 2012), ou seja, entende-se por variável o que pode ser estudado pelo método empírico de forma qualitativa e/ou quantitativa. Por exemplo, peso, altura, nível de instrução, aprendizagem.

Em pesquisas de caráter exploratório, nas quais se busca conhecer melhor sobre o tema e o fenômeno, não existem variáveis a serem declaradas, pois esse tipo de pesquisa serve exatamente para revelá-las (WALDEMAR et al., 2007). Segundo Volpato (2011), os tipos de variáveis são: (1) 
variável operacional e variável teórica; (2) variável independente, variável dependente e variável moderadora e (3) variável necessária e variável suficiente. Uma variável pode se encaixar em um ou mais desses tipos.

A variável operacional é a que se pode registrar diretamente, isto é, aquela que o pesquisador consegue medir de forma concreta e direta na natureza. Assim, definir operacionalmente uma variável é torná-la passível de observação e de mensuração (GIL, 2010). As variáveis operacionais podem ter diferentes níveis de mensuração: nominal (exemplos: gênero, cor, estado civil), ordinal (exemplo: nível de escolarização) ou intervalar (exemplos: peso, idade, salário, número de acidentes). As variáveis operacionais devem ser descritas nas seções de metodologia e resultados dos trabalhos acadêmicos (VOLPATO, 2011).

No entanto a ciência visa, principalmente, às variáveis teóricas (VOLPATO, 2011). A variável teórica é a que pode ser inferida a partir das variáveis operacionais. Por exemplo, as variáveis crescimento, aprendizagem e inteligência. Para o autor, as variáveis teóricas devem aparecer nas seções: título, introdução (objetivos), discussão e conclusão dos trabalhos acadêmicos.

Quando a associação entre as variáveis é com interferência, as variáveis podem ser independentes, dependentes e moderadoras (VOLPATO, 2015). A variável independente é aquela que, manipulada, causa ou contribui para a ocorrência de algum efeito na variável dependente. Portanto, a variável dependente é aquela que se modifica (total ou parcialmente) em função da variável independente. Todavia definir qual será a variável independente e qual será a dependente está relacionado com o foco do estudo e a lógica de raciocínio do pesquisador. Por exemplo: rachadura (independente) influencia o desmoronamento (dependente); chute (independente) influencia o deslocamento da bola (dependente).

Já a variável moderadora (interveniente) é aquele fator, fenômeno ou propriedade que também impacta a variável dependente, porém em menor grau (LAKATOS; MARCONI, 2010). Em outras palavras, é a variável que modifica a variável dependente sem que a variável independente seja alterada (MASCARENHAS, 2012). Logo, a variável moderadora pode 
reforçar, modificar ou eliminar a relação entre as variáveis independente e dependente. Logo, a variável moderadora deve ser controlada para não interferir no estudo. Por exemplo, "a ingestão de bebidas alcoólicas produzirá embriaguez, porém somente se a quantidade ingerida for elevada" (LAKATOS; MARCONI, 1991, p. 180). A variável independente é "ingestão de bebida alcoólica", a dependente é "embriaguez" e a variável moderadora é "volume ingerido de bebida".

No caso de variáveis que se relacionam pela interferência de uma sobre a outra (associação com interferência), a variável necessária é aquela em que a interferência não ocorrerá (não acontece) sem ela, porém a presença dela não garante a interferência. Já a variável suficiente consegue sozinha provocar a interferência, isto é, a presença dela garante a interferência. Por exemplo, o susto é necessário para aumentar a frequência cardíaca, mas não é suficiente, pois essa elevação pode ocorrer por outros fatores.

\section{CLASSIFICAÇÃO DA PESQUISA}

Existem várias formas de classificar as pesquisas e, de acordo com a classificação, define-se o conjunto de procedimentos a serem realizados no estudo. A classificação da pesquisa a enquadra em um tipo de pesquisa ou método de pesquisa, e pode levar em consideração: (1) o propósito geral de pesquisa; (2) os procedimentos técnicos utilizados; (3) a forma ou abordagem do problema; (4) o tempo de pesquisa ou (5) as bases lógicas de investigação.

Quanto ao propósito geral, as pesquisas podem ser classificadas em pesquisa exploratória, pesquisa descritiva ou pesquisa explicativa (GIL, 2010). A pesquisa exploratória visa construir hipóteses ou explicitar um problema, tornando-o mais familiar (GIL, 2010). Para o autor, levantamentos de campo e pesquisas bibliográficas são exemplos de estudos exploratórios. Segundo Waldemar et al. (2007), esse tipo de pesquisa é mais indicado nos estágios iniciais de investigação.

A pesquisa descritiva visa descrever as características de uma população ou variável (GIL, 2010; VOLPATO, 2011). Esse tipo de pesquisa pode, também, descrever as relações entre variáveis (WALDEMAR et al., 2007; GIL, 2010) em uma associação sem interferência (VOLPATO, 2011). Neste 
caso, uma variável não interfere na outra e a associação se dá por uma terceira variável. Assim, o interesse é descrever como as variáveis estudadas estão relacionadas, ou seja, alterando-se uma, o que se pode inferir sobre a outra. Por exemplo: (1) avaliar se a cor da nuvem está relacionada com a ocorrência de chuva (90\% das nuvens escuras resultam em chuva) (VOLPATO, 2011) e (2) avaliar se cachorros com pelos longos são mais resistentes a bactérias (VOLPATO, 2015).

A pesquisa explicativa visa estudar a associação entre variáveis de tal forma que exista interferência entre elas (VOLPATO, 2011). Neste caso, existe um fator ou mecanismo que contribui com ou determina a interferência entre as variáveis (GIL, 2010). Para Volpato (2011), esse mecanismo, por exemplo, pode ser do tipo: biológico, psicológico, político, genético, farmacológico. Por exemplo, (1) testar se a alimentação diária com folhas de alface reduz a ansiedade (VOLPATO, 2015) e (2) testar se a junção da apresentação (powerpoint) com debates em classe facilitam a fixação de conceitos de metafísica em alunos do ensino médio de escola pública. Assim, por explicar a razão ou causalidade entre variáveis, esse tipo de pesquisa é um dos que mais aprofundam o conhecimento da realidade (GIL, 2010).

Vale ressaltar que o conteúdo das variáveis é que permite ao pesquisador presumir se há ou não interferência entre elas, pois a estatística consegue indicar apenas se há associação (VOLPATO, 2011). Ademais, o tipo de pesquisa deve permear todo o texto e influenciar como as partes de um artigo são escritas (VOLPATO, 2011).

Em relação a outros parâmetros, Gil (2010) e Mascarenhas (2012) classificam as pesquisas: (a) quanto aos procedimentos técnicos utilizados: pesquisa bibliográfica, pesquisa documental, pesquisa experimental, pesquisa ex-post-facto, estudo de coorte, levantamento, estudo de campo, estudo de caso, pesquisa ação e pesquisa participante; (b) quanto à forma ou abordagem do problema: pesquisa qualitativa (aquela que interpreta o significado que indivíduos ou grupos atribuem a um problema), pesquisa quantitativa (aquela que relaciona variáveis para testar teorias, geralmente, com emprego de estatística) ou método misto (aquela que combina as 
abordagens qualitativa e quantitativa de forma sinérgica) (CRESWELL, 2010); (c) quanto ao tempo de pesquisa: estudo transversal, estudo longitudinal; (d) quanto às bases lógicas da investigação (MASCARENHAS, 2012): os métodos de abordagem esclarecem acerca dos procedimentos lógicos que deverão ser seguidos no processo de investigação científica dos fatos da natureza e da sociedade. Cada um deles vincula-se a uma das correntes filosóficas que se propõem a explicar como se processa o conhecimento da realidade. O método dedutivo relaciona-se ao racionalismo - o indutivo ao empirismo, o hipotético-dedutivo ao neopositivismo, o dialético ao materialismo dialético e o fenomenológico à fenomenologia (RODRIGUES, 1999).

\section{COLETA DOS DADOS DA PESQUISA}

A coleta de dados visa levantar as informações necessárias para alcançar os objetivos da pesquisa e testar as hipóteses (se houverem) (MASCARENHAS, 2012). Assim, classificada a pesquisa, para a coleta de dados é necessário: caracterizar a população (sujeitos da pesquisa), planejar a amostra (unidade de análise, tipo e justificativa da amostra) e planejar os instrumentos de coleta.

A população é o universo de estudo e a amostra é um subconjunto desse universo. Em relação aos sujeitos da pesquisa (população), eles devem ser caracterizados e selecionados com a definição dos critérios de inclusão e exclusão. Volpato (2011) esclarece que o termo sujeito é genérico e pode ter vários significados, tais como organismo vivo (incluindo o homem), região, material físico (por exemplo, barra de concreto), obra literária, partitura e outros.

No tocante à amostra, inicialmente, vale mencionar que esse termo é mais utilizado quando se trata de pesquisas quantitativas. Recomenda-se que a amostra seja planejada em termos de dimensionamento e composição (MARTINS, 2011). No dimensionamento, calcula-se o tamanho da amostra para o tipo de pesquisa pretendido, e, na composição, define-se o método para estruturação na amostra, que, basicamente, é probabilístico ou não probabilístico (intencional). 
Os dados coletados podem vir de fontes primárias ou secundárias. As fontes primárias são aquelas em que os dados são coletados em primeira mão, isto é, diretamente com os sujeitos da pesquisa. É o caso da entrevista, do questionário, do formulário e da observação. Já nas fontes secundárias, o pesquisador não tem contato direto com os sujeitos da pesquisa, isto é, apenas acessa os dados coletados anteriormente por outros. É o caso da revisão da literatura (VIEIRA, 2008) e do acesso a documentos e bancos de dados. Vale destacar que, uma vez definidos, os instrumentos de coleta de dados devem ser testados antes de serem aplicados para todos os respondentes (GIL, 2010).

Ademais, para escolher um instrumento para coletar os dados, o pesquisador deve guiar-se pelo contexto e pelos objetivos da pesquisa. Os principais instrumentos são (GIL, 2010): (a) questionário: trata-se de uma série ordenada de perguntas (abertas e/ou fechadas) que devem ser respondidas pelo informante. O questionário deve ser objetivo, limitado em extensão e estar acompanhado de instruções que motivem e facilitem o preenchimento. Nesse sentido, a formulação das perguntas deve evitar dubiedades e a indução das respostas; (b) entrevistas: é a situação de obtenção de informações de um entrevistado sobre determinado assunto ou problema. A entrevista pode ser (LAKATOS; MARCONI, 2010): estruturada (roteiro previamente estabelecido e as perguntas fechadas) ou não estruturada (existe roteiro, mas pode-se desviar dele para aprofundar algum item, além de as perguntas serem abertas); (c) formulário: uma coleção de questões anotadas por um entrevistador numa situação face a face com o informante e (d) observação: acompanhamento do objeto de estudo por meio dos sentidos.

\section{ANÁLISE DOS DADOS DA PESQUISA}

A ciência exige que se vá além da coleta de dados e sustente-se interpretações (VOLPATO, 2011). Portanto, após a coleta dos dados, deve-se analisar e interpretar os dados visando fornecer respostas ao problema proposto. Em termos gerais, as etapas para analisar e interpretar os dados são: seleção, categorização, codificação, tabulação, análise e interpretação (GIL, 
2010; MASCARENHAS, 2012). Essas ações estão estreitamente relacionadas e, geralmente, são denominadas, na literatura científica, pelo conjunto como análise de dados ou análise dos resultados.

Em primeiro lugar, tanto nos estudos quantitativos quanto nos qualitativos, é preciso organizar os dados antes de analisá-los. Assim, a seleção consiste em verificar a consistência dos dados em relação a erros, confusões e incompletudes (MARCARENHAS, 2012). Depois, empreende-se a categorização, que é a organização dos dados em categorias de acordo com critérios predefinidos. Em seguida, a codificação envolve o processo pelo qual os dados brutos são transformados em símbolos que podem ser tabulados (GIL, 2010).

Já a tabulação é o processo de agrupar e contar os itens que estão nas várias categorias de análise (MARTINS, 2011). Por conseguinte, a análise tem como objetivo organizar e sumarizar os dados em busca de sentido (GIL, 2010). Para analisar os dados é necessário definir a unidade de análise (o que interessa investigar), que pode ser, por exemplo, uma organização, um grupo ou um indivíduo. Por fim, a interpretação cuida da avaliação das generalizações obtidas com os dados e a inferência de relações causais, além do relacionamento dos dados com a teoria (GIL, 2010).

\section{CRONOGRAMA E ORÇAMENTO DA PESQUISA}

Para complementar o projeto de pesquisa, recomenda-se estimar o tempo e os custos necessários para cumprir a pesquisa, representados, respectivamente, pelas ferramentas: cronograma e orçamento. O cronograma contempla as atividades para realização da pesquisa que vão desde a escolha do tema até a entrega do relatório de pesquisa (trabalho monográfico ou artigo), culminando com a defesa oral, quando pertinente (CAJUEIRO, 2015). Portanto, o cronograma permite, ao pesquisador, visualizar os estágios da pesquisa.

O orçamento estima e sumariza os custos dos recursos necessários para realizar as atividades do projeto de pesquisa. As atividades podem empregar recursos do tipo, por exemplo, humanos, materiais, máquinas e equipamentos (AXELOS, 2017). Assim, todos os itens de custo devem 
ser levantados, tais como: gastos com correspondência, telefone, impressão, fotocópias, compra de livros e equipamentos, gastos com transportes e materiais de escritório, dentre outros. Por fim, vale apontar que, apesar de recomendado, o orçamento não é obrigatório para projetos de pesquisa. 


\section{PROCEDIMENTOS METODOLÓGICOS}

Este artigo visa propor um framework para projetos de pesquisa. Assim, optou-se por uma abordagem exploratória com coleta de dados via revisão da literatura (GIL, 2010) e posterior análise de conteúdo em busca dos conteúdos manifestos (explícitos) (BARDIN, 2009). A pesquisa foi estruturada em dois estágios: pré-análise e exploração do material. Esses são os dois primeiros estágios do framework sugerido por Lukosevicius, Soares e Chaves (2016), que serve como guia para os pesquisadores que queiram aplicar a análise de conteúdo em seus estudos (Quadro 2). Como o estudo não intenciona realizar inferência ou interpretações sobre os conteúdos, mas apenas utilizá-los para desenvolver um framework para projetos de pesquisa, não se avançou para o terceiro estágio "tratamento dos resultados, inferência e interpretação" do framework de Lukosevicius et al. (2016).

Quadro 2 Framework metodológico para análise de conteúdo

\begin{tabular}{|c|c|}
\hline ESTÁGIOS & ATIVIDADES \\
\hline Pré-análise & $\begin{array}{l}\text { - Ler em geral o material (leitura flutuante). } \\
\text { - } \quad \text { Selecionar as amostras (corpus da análise). } \\
\text { - } \quad \text { Elaborar o quadro teórico, o objetivo e as hi- } \\
\text { - } \quad \text { Definir o tipo de grade para análise. } \\
\text { - } \quad \text { Elaborar o esquema de codificação. }\end{array}$ \\
\hline $\begin{array}{l}\text { Exploração do } \\
\text { material }\end{array}$ & $\begin{array}{l}\text { - } \quad \text { Identificar as unidades de análise de conteúdo. } \\
\text { - } \quad \text { Agrupar as unidades de análise de conteúdo } \\
\text { em categorias. } \\
\text { - Descrever as categorias. }\end{array}$ \\
\hline $\begin{array}{c}\text { Tratamento } \\
\text { dos resultados, } \\
\text { inferência e } \\
\text { interpretação }\end{array}$ & $\begin{array}{l}\text { - Tratar os resultados. } \\
\text { - Inferir e/ ou interpretar os resultados. }\end{array}$ \\
\hline
\end{tabular}

Fonte: Lukosevicius et al. (2016) 
No estágio "pré-análise", explorou-se a literatura científica para conhecer melhor o problema pesquisado e recorreu-se a artigos, livros, revistas, jornais, dissertações e teses (GIL, 2010). O critério de escolha dos materiais para o corpus da pesquisa considerou a base de artigos e periódicos da CAPES com base nas palavras de busca "projeto de pesquisa" e "planejamento de pesquisa". Além disso, recorreu-se a livros impressos a respeito de metodologia de pesquisa.

Em seguida, o material foi lido e selecionou-se o corpus da análise, formado por artigos e livros com potencial para oferecer elementos para o estudo sobre o desenvolvimento de projetos de pesquisa. Assim, respeitaram-se os quatro princípios básicos de validade para estudos de análise de conteúdo: (1) exaustividade: levantar todo o material necessário para análise; (2) representatividade: o corpus deve representar o universo da pesquisa; (3) homogeneidade: o corpus ser escolhido com base nos mesmos critérios e (4) pertinência: os materiais selecionados devem proporcionar a informação adequada para cumprir os objetivos da pesquisa (MINAYO, 1994; BARDIN, 2009; RICHARDSON et al., 2010).

Em seguida, definiu-se a grade do tipo mista para a análise de conteúdo. O termo grade significa o tipo de abordagem a ser utilizada para identificação das categorias. A grade mista conjuga as lógicas dedutiva e indutiva, identificando as categorias a priori, porém podendo-se incluir, excluir ou modificar categorias a posteriori, à medida que a exploração do material ocorra. Por exemplo, neste estudo, houve três conjuntos de categorias: finais, intermediárias e iniciais. As categorias finais e parte das categorias iniciais foram definidas a priori, porém as categorias intermediárias foram definidas a posteriori.

No estágio "exploração do material", o critério de classificação foi baseado em documentos completos (artigos e livros), porém a unidade de registro é temática. Por fim, as categorias foram descritas tendo por referência as unidades de registro (BARDIN, 2009) e os resultados foram analisados pela justaposição das categorias (SILVA; FOSSA, 2013) com vias a responder à questão de pesquisa. 


\section{APRESENTAÇÃO E ANÁLISE DOS RESULTADOS}

Este artigo exploratório visou propor um framework para projetos de pesquisa que possa auxiliar pesquisadores, sobretudo, iniciantes, a planejarem suas pesquisas. Para desenvolvê-lo, utilizou-se revisão da literatura (ver seção neste artigo) para a coleta de dados e análise de conteúdo (LUKOSEVICIUS et al., 2016) para análise dos resultados. A aplicação da análise de conteúdo sobre o corpus da análise produziu três conjuntos de categorias, conforme Quadro 3.

Quadro 3 Relacionamento entre as categorias iniciais, intermediárias e finais do estudo

\begin{tabular}{|lll|}
\hline \multicolumn{1}{|c}{$\begin{array}{c}\text { Categorias } \\
\text { Finais }\end{array}$} & \multicolumn{1}{c|}{$\begin{array}{c}\text { Categorias } \\
\text { Intermediárias }\end{array}$} & \multicolumn{1}{c|}{ Categorias Iniciais } \\
& 1.1 Por que & 1.1.1 Justificativa (GAP e relevância) \\
1. Título, & & 1.2 .1 Título \\
introdução & & 1.2 .2 Tema (contexto) \\
e referencial & 1.2 O que & 1.2.3 Problema (pergunta) \\
teórico & & 1.2 .4 Objetivo geral \\
& & 1.2 .6 Objetivos específicos \\
& & 1.2 .7 Referencial teórico \\
& & 2.1.1 Variável(is) \\
2. Metodologia & 2.1 Como, & 2.1.2 Classificação \\
& Onde e Quem & 2.1.3 Coleta dos dados \\
& & 2.1.4 Análise dos dados \\
3. Cronograma & 3.1 Quando & 3.1.1 Cronograma \\
4. Orçamento & 4.1 Quanto & 4.1.1 Orçamento \\
\hline
\end{tabular}

As 14 categorias iniciais foram extraídas diretamente dos elementos da revisão da literatura expostos anteriormente. As cinco categorias intermediárias basearam-se no proposto por Waldemar et al. (2007) no sentido 
de que, na elaboração do projeto de pesquisa, é imprescindível responder aos questionamentos que norteiam o trabalho: por quê?, o que?, como?, onde?, quem?, quando? e quanto?. Já as quatro categorias finais apoiaram-se nos componentes recomendados para um projeto de pesquisa, são eles: título, introdução, referencial teórico, metodologia, cronograma e orçamento. Vale lembrar que o projeto de pesquisa contém as ações futuras para realização da pesquisa, portanto, não possui as seções de resultados, discussão e conclusão (COSTA; COSTA, 2011).

Portanto, as 14 categorias iniciais foram organizadas em cinco categorias intermediárias, que, por sua vez, foram organizadas em quatro categorias finais, conforme Figura 1. As categorias são:

- Iniciais: (1) título; (2) tema (contexto); (3) justificativa (GAP e relevância); (4) problema (pergunta); (5) objetivo geral; (6) objetivos específicos; (7) variável(is); (8) hipótese(s) ou pressuposto(s); (9) referencial teórico; (10) classificação; (11) coleta de dados; (12) análise dos dados; (13) cronograma e (14) orçamento.

- Intermediárias: (1) por que; (2) o que; (3) como, onde e quem; (4) quando e (5) quanto.

- Finais: (1) título, introdução e referencial teórico; (2) metodologia; (3) cronograma e (4) orçamento. 
Figura 1 Framework Research Project Model Canvas (RPMC)

\begin{tabular}{|c|c|c|}
\hline \multicolumn{3}{|l|}{\begin{tabular}{l|l} 
TÍTULO & O que? $\uparrow$
\end{tabular}} \\
\hline TEMA (Contexto) & VARIÁVEL(is) & CLASSIFICAÇÃO \\
\hline \multirow{3}{*}{$\begin{array}{c}\text { O que? } \\
\text { (Introdução) }\end{array}$} & \multirow{4}{*}{$\begin{array}{c}\text { Como? Onde? Quem? } \\
\text { (Metodologia) }\end{array}$} & $\rightarrow \quad$ Como? Onde? \\
\hline & & Quem? (Metodologia) \\
\hline & & $\begin{array}{c}\text { COLETA } \\
\text { DOS DADOS }\end{array}$ \\
\hline $\begin{array}{c}\text { JUSTIFICATIVA } \\
\text { (GAP e Relevância) }\end{array}$ & & \multirow{2}{*}{$\begin{array}{l}\text { Como? Onde? Quem? } \\
\text { (Metodologia) }\end{array}$} \\
\hline $\begin{array}{c}\text { Por que? } \\
\text { (Introdução) }\end{array}$ & $\begin{array}{l}\text { HIPÓTESE }(s) \text { ou } \\
\text { PRESSUPOSTO }(s)\end{array}$ & \\
\hline $\begin{array}{l}\text { PROBLEMA } \\
\text { (Pergunta) }\end{array}$ & $\begin{array}{c}\text { O que? } \\
\text { (Introdução) }\end{array}$ & $\begin{array}{c}\text { ANÁLISE } \\
\text { DOS DADOS }\end{array}$ \\
\hline $\begin{array}{c}\text { O que? } \\
\text { (Introdução) }\end{array}$ & $\begin{array}{c}\text { REFERENCIAL } \\
\text { TEÓRICO } \\
\end{array}$ & \multirow{3}{*}{$\begin{array}{l}\text { Como? Onde? Quem? } \\
\text { (Metodologia) }\end{array}$} \\
\hline $\begin{array}{l}\text { OBJETIVO } \\
\text { GERAL } \\
\end{array}$ & \multirow{2}{*}{$\begin{aligned} & \text { O que? } \\
& \text { (Referencial } \\
& \rightarrow \text { Teórico) }\end{aligned}$} & \\
\hline $\begin{array}{c}\text { O que? } \\
\text { (Introdução) }\end{array}$ & & \\
\hline $\begin{array}{c}\text { OBJETIVOS } \\
\text { ESPECÍFICOS }\end{array}$ & CRONOGRAMA & ORÇAMENTO \\
\hline $\begin{array}{c}\text { O que? } \\
\text { (Introdução) }\end{array}$ & $\begin{array}{c}\text { Quando? } \\
\longrightarrow \text { (Cronograma) } \\
\end{array}$ & $\begin{array}{c}\text { Quanto? } \\
\longrightarrow \quad \text { (Orçamento) }\end{array}$ \\
\hline
\end{tabular}

As 14 categorias iniciais deram origem aos blocos do framework denominado Research Project Model Canvas (RPMC). A Figura 1 apresenta os 14 blocos do framework (um para cada categoria) e o significado de cada bloco foi explicado anteriormente na revisão da literatura. Ademais, segue-se um possível fluxo de elaboração que, conforme Pontes, Filho e Costa (2005), pode ser alterado pelo pesquisador dado que o planejamento é um processo criativo com base em pensamento não linear. 
Nesse sentido, o fluxo sugerido para se estruturar um projeto de pesquisa é: em primeiro lugar, define-se e delimita-se o tema de pesquisa provendo, também, uma visão a respeito do contexto do estudo. Feito isso, pode-se sugerir um título inicial, dado que provavelmente será alterado ao longo do trabalho. Depois, justifica-se o trabalho explicitando-se o GAP e a relevância da pesquisa. A seguir, define-se o problema de pesquisa por meio de uma pergunta, sendo que o problema proverá os elementos para a definição dos objetivos geral e específicos da pesquisa. O objetivo geral se apropria das palavras utilizadas no problema, porém em tom afirmativo. Já os objetivos específicos detalham as etapas para se atingir o objetivo geral. Essas etapas servirão para a elaboração do cronograma da pesquisa, pois cada etapa transformar-se-á em uma atividade do cronograma. Ao alocar recursos em cada atividade do cronograma, pode-se calcular o orçamento do projeto a partir dos recursos alocados.

Com base nos objetivos, pode-se, também, estabelecer o referencial teórico com as teorias de suporte ao estudo. Dando prosseguimento, pôde-se elencar as hipóteses (em caso de pesquisa quantitativa) ou pressupostos/suposições (em caso de pesquisa qualitativa), lembrando que existem estudos que não demandam esses itens. Em sequência, como as hipóteses / pressupostos são declarações afirmativas, elas proveem informações para a definição e tipificação das variáveis. Em seguida, a pesquisa é classificada em um ou mais tipos de pesquisa. Com isso pronto, explicita-se a população (sujeitos), o dimensionamento e a composição da amostra, além dos instrumentos para coleta de dados. Então, apontam-se as abordagens para a análise dos dados. Como exemplo de aplicação, a Figura 2 apresenta o framework RPMC empregado no planejamento deste artigo. 
Figura 2 Exemplo de aplicação do framework RPMC

\begin{tabular}{|c|c|c|c|}
\hline TÍTULO & \multicolumn{3}{|c|}{$\begin{array}{l}\text { Executar é preciso, Planejar não é preciso: proposta de fra- } \\
\text { mework para projetos de pesquisa }\end{array}$} \\
\hline \multicolumn{2}{|c|}{ TEMA (Contexto) } & VARIÁVEL(is) & CLASSIFICAÇÃO \\
\hline \multirow{2}{*}{\multicolumn{2}{|c|}{ Projetos de pesquisa }} & \multirow{3}{*}{$\begin{array}{l}\text { Não se aplica } \\
\text { (pesquisa } \\
\text { exploratória) }\end{array}$} & tória \\
\hline & & & $\begin{array}{c}\text { COLETA } \\
\text { DOS DADOS }\end{array}$ \\
\hline $\begin{array}{r}\text { JUSTIFIC } \\
\text { e Re }\end{array}$ & $\begin{array}{l}\text { IVA (GAP } \\
\text { ncia) }\end{array}$ & & \multirow{3}{*}{$\begin{array}{l}\text { Sujeitos: artigos e } \\
\text { livros } \\
\text { Abordagem: revisão } \\
\text { da literatura }\end{array}$} \\
\hline $\begin{array}{l}\text { 1. Proj } \\
\text { elaborad }\end{array}$ & $\begin{array}{l}\text { tos mal } \\
\text { s levam à }\end{array}$ & $\begin{array}{l}\text { HIPÓTES } \\
\text { PRESSUP( }\end{array}$ & \\
\hline $\begin{array}{r}\text { rejeição } \\
\text { 2. A qualid } \\
\text { to influenc } \\
\text { de do tra }\end{array}$ & $\begin{array}{l}\text { artigos } \\
\text { e do proje- } \\
\text { a qualida- } \\
\text { lho final }\end{array}$ & \multirow{2}{*}{$\begin{array}{l}\text { Não se aplica } \\
\text { (pesquisa } \\
\text { exploratória) }\end{array}$} & \\
\hline $\begin{array}{r}\text { PROI } \\
\text { (Per) }\end{array}$ & $\begin{array}{l}\text { MA } \\
\text { ta) }\end{array}$ & & $\begin{array}{r}\text { AN } \\
\text { DOS }\end{array}$ \\
\hline \multirow{2}{*}{\multicolumn{2}{|c|}{$\begin{array}{l}\text { Quais são as alternativas } \\
\text { gráficas para se } \\
\text { estruturar projetos de } \\
\text { pesquisa? }\end{array}$}} & $\begin{array}{r}\text { REFERE } \\
\text { TEÓF }\end{array}$ & $\begin{array}{l}\text { Análise de conteúdo } \\
\text { Framework de }\end{array}$ \\
\hline & & $\begin{array}{l}\text { Literatura sobre pro- } \\
\text { jetos de pesquisa }\end{array}$ & $\begin{array}{l}\text { Lukosevicius et al., } \\
\qquad(2016)\end{array}$ \\
\hline \multicolumn{2}{|c|}{ OBJETIVO GERAL } & (Richardson et al., & Grade mista de análise \\
\hline \multicolumn{2}{|c|}{$\begin{array}{c}\text { Propor uma } \\
\text { abordagem gráfica } \\
\text { para a estruturação de } \\
\text { projetos de pesquisa }\end{array}$} & $\begin{array}{l}\text { 1999; Creswell, 2010; } \\
\text { Gil, 2010; Ferreira, } \\
\text { 2015; Lukosevicius et } \\
\text { al., 2016 e outros) }\end{array}$ & $\begin{array}{l}\text { Unidade de registro } \\
\text { temática } \\
\text { Justaposição de } \\
\text { categorias }\end{array}$ \\
\hline \multicolumn{2}{|c|}{$\begin{array}{l}\text { OBJETIVOS } \\
\text { ESPECÍFICOS }\end{array}$} & CRONOG & ORÇAMENTO \\
\hline \multicolumn{2}{|c|}{$\begin{array}{l}\text { 1. Levantar formatos } \\
\text { visuais para projetos de } \\
\text { pesquisa; } \\
\text { 2. Criar e testar o } \\
\text { framework; } \\
\text { 3. Escrever o artigo }\end{array}$} & $\begin{array}{c}\text { 1. um mês } \\
\text { (Dez/ 2016) } \\
\text { 2. um mês } \\
\text { (Jan/ 2017) } \\
\text { 3. } 2 \text { meses } \\
\text { (Fev e Mar/ 2017) }\end{array}$ & $\begin{array}{c}\text { Não se aplica } \\
\text { (recursos próprios) }\end{array}$ \\
\hline
\end{tabular}


Por fim, Ferreira (2015) atesta ser benéfico projetar um artigo antes de começar a escrevê-lo, mesmo que haja alterações ao longo do tempo, porque aumenta a probabilidade de aceitação do trabalho em periódicos científicos.

Ademais, por ser gráfico, lúdico e integrado, o RPMC pode estimular nos pesquisadores e estudantes de administração o apreço pelo planejamento das pesquisas, podendo resultar em melhores trabalhos científicos. Por exemplo, alguns benefícios que o RPMC pode trazer para a definição dos projetos de pesquisa: (1) utilizar linguagem visual e lúdica para planejar a pesquisa; (2) mostrar uma visão geral sobre a pesquisa em uma única imagem (big picture); (3) permitir entender como os componentes do projeto de pesquisa se integram; (4) permitir o planejamento coletivo da pesquisa; (5) facilitar a comunicação e a venda da pesquisa para agentes internos e externos e (6) reduzir o tempo para se gerar a primeira versão do projeto de pesquisa. 


\section{CONSIDERAÇÕES FINAIS}

Esta pesquisa exploratória com apoio de revisão da literatura e análise de conteúdo propôs um framework para estruturar projetos de pesquisa. $\mathrm{O}$ framework, denominado Research Project Model Canvas (RPMC), provê direcionamento ao pesquisador, auxiliando-o a evitar erros, mas sem lhe suprimir a criatividade e o espaço da tomada de decisão.

Percebeu-se que o framework RPMC, em relação à abordagem tradicional em texto corrido, permite planejar uma pesquisa de forma gráfica, integrada e lúdica, provendo ao pesquisador uma visão global dos elementos de um projeto de pesquisa. Assim, o framework proposto pode estimular os pesquisadores em geral, sobretudo, os iniciantes, a planejarem suas pesquisas colhendo os benefícios intrínsecos do planejamento.

As contribuições práticas do framework residem no: (1) encurtamento da duração para se planejar uma pesquisa, (2) na facilidade para que mais de um pesquisador contribua com o projeto de pesquisa e (3) na melhora da comunicação e venda da pesquisa para agentes internos e externos. Em termos teóricos, as principais contribuições do framework são: (1) a proposta de formato alternativo ao texto corrido para o projeto de pesquisa com o emprego de abordagem lúdica e visual e (2) a visão integrada dos elementos do projeto de pesquisa, permitindo o entendimento global da pesquisa.

Como limitação desta pesquisa, o framework, como todo instrumento, pode não abranger as diversas gamas de pesquisa nem abarcar todas as particularidades delas. Em termos de estudos futuros, pode-se incluir a aplicação do framework proposto nos diversos tipos de pesquisa para confirmar-lhe a efetividade. Ademais, sugere-se averiguar o emprego do framework por professores de administração, notadamente em disciplinas de metodologia de pesquisa, buscando entender o seu impacto nos resultados dos alunos em relação ao: (1) aprendizado dos conceitos de metodologia científica, (2) estímulo ao planejamento de pesquisa e (3) aceitação dos trabalhos decorrentes em eventos/periódicos científicos. 
Por fim, espera-se que esta pesquisa fomente a importante atividade de planejamento das pesquisas, tornando os projetos de pesquisa mais simples, objetivos, visuais e, por que não, mais divertidos e lúdicos de se elaborar. 


\section{REFERÊNCIAS}

AXELOS. Managing successful projects with PRINCE2. Norwich: TSO, 2017.

BACHARACH, S. Organizational theories: some criteria for evaluation. Academy of Management Review, v. 14, n. 4, p. 496-515, 1989. doi: 10.5465/AMR.1989.4308374

BARDIN, L. Análise de Conteúdo. Lisboa: Edições 70, 2009.

BARROS, A. J. S. S.; LEHFELD, N. A. S. Fundamentos da metodologia científica. São Paulo: Pearson Prentice Hall, 2007.

BARRAL, W. Metodologia da pesquisa jurídica. 2. ed. Florianópolis: Fundação Boitex, 2003.

BARRETO, A. V. P.; HONORATO, C. F. Manual de sobrevivência na selva acadêmica. Rio de Janeiro: Objeto Direto, 1998.

BENBASAT, I; GOLDSTEIN, D; MEAD, M. The case research strategy in studies of information systems. MIS Quarterly, v. 11, n. 3, p. 369-386, 1987. doi: 10.2307/248684

BURSZTYN, M.; DRUMMOND, J. A.; NASCIMENTO, E. P. Como escrever (e publicar) um trabalho científico. Rio de Janeiro: Garamond, 2010.

CAJUEIRO, R. L. P. Manual para elaboração de trabalhos acadêmicos: guia prático do estudante. 3. ed. Petrópolis: Vozes, 2015.

COSTA, M. A. F.; COSTA, M. F. B. Projeto de pesquisa: entenda e faça. 2. ed. São Paulo: Vozes, 2011.

CRESWELL, J. W. Projeto de pesquisa: métodos qualitativo, quantitativo e misto. 3. ed. Porto Alegre: Artmed, 2010.

FALASTER, C. D.; FERREIRA, M. A. S. P.; CANELA, R. Motivos de rejeição dos artigos nos periódicos de administração. Organizações \& Sociedade. Salvador, v. 23, n. 77, p. 285 306, 2016. doi: $10.1590 / 1984-9230776$

FIGUEIREDO, N. M. A. Método e metodologia na pesquisa científica. São Caetano do Sul: Yendis, 2008.

FERREIRA, M. P. Pesquisa em administração e ciências sociais aplicadas: um guia para a publicação de artigos acadêmicos. Rio de Janeiro: LTC, 2015.

GIL, A. C. Estudo de caso. São Paulo: Atlas, 2009.

GIL, A. C. Como elaborar projetos de pesquisa. 5. ed. São Paulo: Atlas, 2010.

HADDAD, N. Metodologia de estudos em ciências da saúde: como planejar, analisar e apresentar um trabalho científico. São Paulo: Roca, 2004.

GODOY, A. S. Introdução à pesquisa qualitativa e suas possibilidades. Revista de Administração de Empresas, v. 35, n. 2, p. 57-63, 1995. doi: 10.1590/S0034-75901995000200008 
LAKATOS, E. M.; MARCONI, M. A. Fundamentos de metodologia científica. 7. ed. São Paulo: Atlas, 2010.

LAKATOS, E. M.; MARCONI, M. A. Metodologia científica. 3. ed. São Paulo: Atlas, 1991.

LUKOSEVICIUS, A. P.; SOARES, C. A. P.; CHAVES, M. S. Análise de conteúdo em gerenciamento de projetos: proposta de um framework metodológico. Iberoamerican Journal of Project Management (IJoPM), v. 7, n. 2, p. 29-53, 2016.

MARSCH, D.; FURLONG, P. A skin, not a sweater: ontology and epistemology in political science. In: MARSCH, D; STOKER, G. Theory and method in political science. London: Pallgrave McMillan, 2002.

MARTINS, A. G. Manual para elaboração de monografias e dissertações. 3. ed. São Paulo: Atlas, 2010.

MARTINS, G. A. Metodologia da pesquisa: conceitos e técnicas. 3. ed. São Paulo: Atlas, 2011.

MASCARENHAS, S. A. Metodologia científica. São Paulo: Pearson Education do Brasil, 2012.

MINAYO, M. C. S. (Org.). Pesquisa social: teoria, método e criatividade. 2. ed. Rio de Janeiro: Vozes, 1994.

MERRIAM, S. B. Qualitative research and case study applications in education. São Francisco (CA): Jossey-Bass, 1998.

OSTERWALDER, A.; PIGNEUS, Y. Business model generation, inovação em modelos de negócios: um manual para visionários, inovadores e revolucionários. Rio de Janeiro: Alta Books, 2011.

PONTES, C. A.; FILHO, A. M.; COSTA, A. M. O processo criativo e a tessitura de projetos acadêmicos de pesquisa. Interface - comunicação, saúde e educação, v. 9, n. 17, p. 439-450, 2005. doi: 10.1590/S1414-32832005000200025

PENDERGAST, G. The art of reviewing. International Journal of Advertising, v. 26, n. 2, p. 277-280, 2007. doi: 10.1080/02650487.2005.11072917

PERNEGER, T. V.; HUDELSON, P. M. Writing a research article: advice to beginners. International Journal for Quality in Health Care, v. 16, n. 3, p. 191-192, 2004. doi: 10.1093/ intqhe/mzh053

RICHARDSON, R. J. (Org.). Pesquisa social: métodos e técnicas. 3. ed. São Paulo: Atlas, 2010.

RODRIGUES, M. G. V. (Org.). Metodologia da pesquisa: elaboração de projetos, trabalhos acadêmicos e dissertações em ciências militares. 2. ed. Rio de Janeiro: EsAO, 1999.

SILVA, A. H.; FOSSA, M. I. T. Análise de conteúdo: exemplo de aplicação da técnica para análise de dados qualitativos. In: IV ENCONTRO DE ENSINO E PESQUISA DE ADMI- 
NISTRAÇÃO E CONTABILIDADE (ENEPQ). Anais... Brasília, Distrito Federal, Brasil, 2013.

VERGARA, S. C. Projetos e relatórios de pesquisa em administração. 3. ed. São Paulo: Atlas, 2004.

VIEIRA, S. Como escrever uma tese. 6. ed. São Paulo: Atlas, 2008.

VOLPATO, G. L. Método lógico para redação científica. Botucatu: Best Writing, 2011.

VOLPATO, G. L. Guia prático para a redação científica. Botucatu: Best Writing, 2015.

WALDEMAR, P. J.; PEREIRA, V. L. D. V.; FILHO, H. V. P. Pesquisa científica sem tropeços: abordagem sistêmica. São Paulo: Atlas, 2007.

WHETTEN, D. What constitutes a theoretical contribution? Academy of Management Review, v. 14, n. 4, p. 490-495, 1989. 


\section{DADOS DOS AUTORES}

\section{ALESSANDRO PRUDÊNCIO LUKOSEVICIUS ${ }^{\star}$ alessanpl@gmail.com} Doutor em Engenharia Civil pela UFF

Instituição de vinculação: Universidade Federal Fluminense

Niterói / RJ - Brasil

Áreas de interesse em pesquisa: Gerenciamento de projetos; Ciência das redes;

Metodologia científica.

^Rua Passo da Pátria, 156, $3^{\circ}$ andar Boa Viagem Niterói/RJ 22320-000 